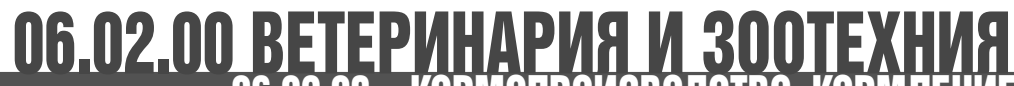 \\ $0,02,08$ -

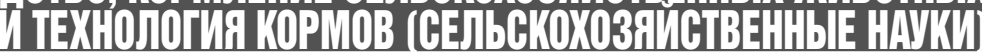

\section{ОБМЕН ВЕЩЕСТВ И ЭНЕРГИИ У МОЛОДНЯКА СВИНЕЙ НА ОТКОРМЕ ПРИ СКАРМЛИВАНИИ КОРМОСМЕСИ С ПРОБИОТИЧЕСКОЙ ДОБАВКОЙ}

Гамко Леонид Никифорович, доктор сельскохозяйственных наук, профрессор кафредры "Кормление животных, частная зоотехния и переработка продуктов животноводства»

Сидоров Иван Иванович, кандидат биологических наук, директор ФГБУ Брянская МВЛ

Менякина Анна Георгиевна, доктор сельскохозяйственных наук, доцент кафедры "Кормление животных, частная зоотехния и переработка продуктов животноводства»

ФГБОУ ВО Брянский государственный аграрный университет

243365, Брянская область, Выгоничский район, с. Кокино, ул. Советская, д. $2 a$

+79102357733, e-mail: menyakina77@yandex.ru,+79092439588,e-mail:gamkol@mail.ru

Ключевые слова: молодняк свиней, кормосмесь, продуктивность, переваримость, баланс, убойные и мясные качества.

В статье приведены результаты исследований по скармливанию кормосмеси молодняку свиней на откорме с включением в ее состав 300 и 350г/m пробиотической добавки при ежедневном скармливании 2, 23 кг кормосмеси в среднем за опыт. Объектом исследований явился молодняк свиней на откорме крупной белой породы средней живой массой 38,6 -39,0 кг и пробиотическая добавка «Проваген». Молодняк свиней для опыта был отобран от свиноматок, которым скармливали за 30 дней до опороса пробиотическую добавку в тех же дозах в составе кормосмеси. Абсолютный прирост живой массы за учетный период составил в контрольной группе 60,4, во второй опытной группе 61,5 и в третьей 62,0 кг. Среднесуточный прирост составил соответственно 525, 535 и 539 г. Коэффициенты переваримости питательных веществ кормосмеси с пробиотической добавкой были несколько больще, особенно в третьей опытной группе - сырого жира и сырой клетчатки на 4,1 и 49,8\%.Среднесуточный баланс азота, кальция и фосфора были положительными. Удержано в теле молодняка свиней азота во второй опытной группе на 10,9 и в третьей на 21,2\% больще в сравнении с контролем. Морфологические и биохимические показатели крови были в пределах физиологической нормы. Скармливание пробиотической добавки в составе кормосмеси для молодняка свиней на откорме позволило при комплексном исследовании выявить наиболее эффрективную дозу включения в состав кормосмеси пробиотической добавки - 350г/m.

\section{Введение}

Приоритетным направлением аграрной политики России является продовольственная безопасность, которая находится в зависимости от ряда факторов, коренным образом влияющих на эффективность производства свинины. Важнейшим условием повышения эффективности отрасли свиноводства является улучшение продуктивности молодняка свиней на откорме с учётом улучшения качества комбикормов, а на небольших фермах КФХ за счёт повышения качества скармливаемых кормосмесей. Для этих целей необходимо использовать разные добавки, владеющие ростстимулирующим эффектом. В последние два десятилетия наиболее значительный интерес представляют пробиотические препараты, созданные на основе культур симбиотных микроорганизмов [1-6]. На современном этапе имеются обширные данные исследований в области кормления, проведенных с целью из- учения не только безопасности, но и благотворного воздействия на процессы, связанные с пищеварением (аппетитом, полнотой поедаемости суточного рациона, переваримости пищевых нутриентов, их доступности для дальнейшей трансформации). Накоплен обширный опыт по применению добавок разной химической природы, компенсирующих дефицит аминокислот, витаминов и минеральной составляющей рационов, но добавки с пробиотическим действием изучены не в полной мере [7-16].

Производство продукции животноводства в Брянском регионе сопряжено с негативными экологическими факторами, накладывающими обязательство к дополнительным мерам по обеспечению получения «чистой продукции» высокого качества. В этой связи, при скармливании разных доз пробиотической добавки в составе кормосмеси молодняку свиней на откорме в отличие от других ростстимулирующих добавок 
являются экологически чистыми препаратами, безвредными для животных.

\section{Материалы и методы исследований}

Объектами наших исследований явились - пробиотическая добавка «Проваген» (в ее составе: Bacillus licheniformis (ВКMB-2414) и Bacillus subtilis (ВKMB-2287) в соотношении 1:1 KOE/1 г =1: $10^{9}$ ) и свиньи в период откорма (порода - крупная белая). Добавку пробиотика «Проваген» изучали в двух дозировках по 300 и 350 г/т в составе кормосмеси. Для проведения опыта были отобрано три группы свиней по 12 голов в каждой-аналогов по живой массе, энергии роста и происхождению. Молодняк свиней для опыта был отобран от свиноматок, которым скармливали за 30 дней до опороса пробиотическую добавку в составе кормосмеси в тех же дозах. Алгоритм проведения научно-хозяйственного опыта, поставленного в условиях свинофермы СПК Агрофирма «Культура», приведен в таблице 1.

Таблица 1

Схема научно-хозяйственного опыта

\begin{tabular}{|l|c|}
\hline \multicolumn{1}{|c|}{ Группа } & Условия кормления \\
\hline I- контрольная & ОР* (основной рацион) \\
\hline II- опытная & $\begin{array}{c}\text { OP + 300 г/т пробиотической добавки } \\
\text { «Проваген» }\end{array}$ \\
\hline III- опытная & $\begin{array}{c}\text { OP + 350 г/т пробиотической добавки } \\
\text { «Проваген» }\end{array}$ \\
\hline
\end{tabular}

ОР* (основной рацион) - кормосмесь

Молодняку свиней на откорме скармливали кормосмесь, в состав которой входили следующие корма: \%, пшеница фуражная - 28,0; ячмень - 40,0; овёс - 5,0; люпин сладкий 10,0; жмых подсолнечный - 2,5; сухая молочная сыворотка - 10,0; мясокостная мука - 2,0; мел кормовой - 1,0; соль поваренная - 1,5. В среднем в сутки за учетный период на голову приходилось 2,23 кг кормосмесей, в которых содержалось 26,9 МДж обменной энергии и 305 г переваримого протеина. В опыте изучали изменение живой массы и среднесуточных приростов путём взвешивания в каждом периоде, обмен веществ и энергии [17]. В конце опыта проводился забор крови животных с последующим определением на биохимическом анализаторе Stat Fax-3300 биохимических и гематологических показателей на базе ФГБУ «Брянская межобластная лаборатория». Убойные и мясные качества молодняка свиней на откорме определяли по общепринятой методике [18]. Полученные в научно-хозяйственном опыте материалы обрабатывали биометрически.

\section{Результаты исследований}

Помимо уровня достижения сбалансированности и полноценности кормления, факторов окружающей среды заметное влияние на показатели продуктивности и уровня энергозатрат физиологически полезной энергии на производство 1 кг прироста живой массы, в период откорма существенное значение имеет соотношение кормов в составе кормосмеси и дозировка обогащающей ее пробиотической добавки. Влияние перечисленных факторов на изменение абсолютного и среднесуточных приростов у откармливаемого молодняка свиней отражено в показателях, приведенных в таблице 2 .

Очевидно, что показатели среднесуточных приростов у сверстников в опытных группах, которым скармливали кормосмесь, включающую 300 и 350 г/т пробиотической добавки, были больше на 1,9 и 2,6\% в сравнении с контрольной группой.

Анализ переваримости пищеварительных веществ кормосмеси основного рациона и кормосмеси, обогащенной пробиотической добавкой «Проваген» в изучаемых дозах, а также использование поступивших с рационом азота, кальция, фосфора и обменной энергии проведён по данным, полученным в ходе физиологического опыта. Для опыта отобрали по три боровка в каждой группе с живой массой, близкой к средней по группе. Животных трёх групп кормили той же кормосмесью, что и в научнохозяйственном опыте. Молодняку свиней контрольной группы скармливали кормосмесь без пробиотической добавки, а опытным группам

Таблица 2

Среднесуточные приросты и энергозатраты на прирост у свиней на откорме при скармливании в составе кормосмеси добавки «Проваген»

\begin{tabular}{|l|c|c|c|}
\hline \multirow{2}{*}{\multicolumn{1}{|c|}{ Показатель }} & \multicolumn{3}{c|}{ Группа } \\
\cline { 2 - 4 } & І- контрольная & II- опытная & III- опытная \\
\hline Живая масса в начале опыта, кг & $39,0 \pm 0,18$ & $38,6 \pm 0,18$ & $38,9 \pm 0,14$ \\
\hline Живая масса в конце опыта, кг & $99,4 \pm 0,33$ & $100,1 \pm 0,20$ & $100,9 \pm 0,25$ \\
\hline Абсолютный прирост массы, кг & 60,4 & 61,5 & 62,0 \\
\hline Среднесуточный прирост, г & $525 \pm 2,63$ & $535 \pm 0,92 * *$ & $539 \pm 2,08 * * *$ \\
\hline \% к контролю & 100,0 & 101,9 & 102,6 \\
\hline Затраты обменной энергии на 1 кг прироста, МДж & 51,2 & 50,2 & 49,9 \\
\hline Затрачено кормосмеси на 1 кг прироста, кг & 4,25 & 4,20 & 4,14 \\
\hline
\end{tabular}


свиней давали кормосмесь с пробиотиком. Коэффициенты переваримости питательных веществ, поступивших с рационом у животных подопытных групп, отражены на рисунке 1.

Анализ полученных данных свидетельствует о том, что переваримость сырого проте-

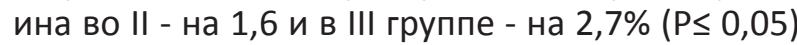
была больше в сравнении с таковыми показателями у животных I группы. При этом, коэффициент переваримости органического вещества практически не различался у всех подопытных животных. Установлено, свиньи III опытной группы, получавшие с кормосмесью «Проваген» из расчёта 350 г/т, лучше $(P \leq 0,05)$ переваривали: сырую клетчатку (на 9,8) и сырой жир (на 4,1\%) по отношению аналогов I группы. Основными показателями питательности комбикормов, кормосмесей для свиней являются: сухое вещество, обменная энергия, незаменимые аминокислоты, являющиеся составной частью сырого протеина, сырой жир, сырая клетчатка, а также кальций и фосфор. На основании баланса азота, кальция, и фосфора можно судить о более качественных изменениях в организме молодняка свиней под влиянием скармливания кормосмеси с пробиотической добавкой (табл. 3).

Анализ данных баланса азота показывает, что в теле свиней в период откорма во II группе на 10,9 \% и в III на 21,1 \% азота удержано больше, чем у аналогов контрольной группы. Полученные результаты свидетельствуют, что баланс азота, кальция и фосфора был положительным, а использование этих веществ молодняком свиней от принятых было больше в опытных группах, которым скармливали пробиотическую добавку.

Картина крови и ее сыворотки (рис. 2 и 3) как нельзя лучше и полной мере отражает состояние и скорость метаболизма в организме, по результатам ее основных показателей можно судить о протекании обменных процессов.

Изученные морфологические показатели крови, образцы которой были взяты у свиней из II и III групп, были сравнительно больше, чем у контрольных сверстников, однако все они находились в пределах допустимых физиологических колебаний. Количество эритроцитов увеличилось на 2,0\%, лейкоцитов -на 1,7\% в крови животных обеих опытных групп, а уровень гемоглобина во II группе повысился на 1,3 и в III группе - на 2,3\%, что свидетельствует об обеспеченности организма кислородом и интенсивности обменных процессов. Молодняк свиней III группы, получавший кормосмесь с пробиотической добавкой 350 г/т кормосмеси, выгодно отличался по содержанию белка в сыворотке крови, которого на 4,2\% было больше в III группе и на 1,6\% - во второй. Очевидно, симбиоз кишечной

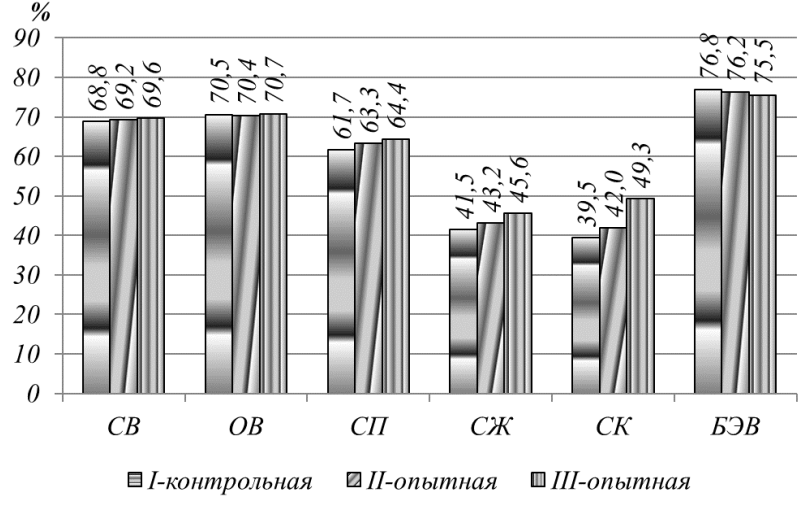

Рис. 1 - Коэффициенты переваримости питательных веществ

Примечание: $C B$ - сухое вещество, $O B$ - органическое вещество, СП-сырой протеин, СЖ-сырой жир, СК - сырая клетчатка, БЭВ - биологические экстрактивные вещества

Таблица 3

Баланс азота и его использование, г/в сутки на голову $(n=3)$

\begin{tabular}{|l|c|c|c|}
\hline \multirow{2}{*}{ Показатель } & \multicolumn{3}{|c|}{ Группа } \\
\cline { 2 - 4 } & $\begin{array}{c}\text { І- кон- } \\
\text { трольная }\end{array}$ & II- опытная & III- опытная \\
\hline \multicolumn{4}{|c|}{ Баланс азота } \\
\hline Принято с кормом & 61,4 & 61,5 & 61,6 \\
\hline Выделено с калом & $23,4 \pm 0,46$ & $22,5 \pm 0,50$ & $21,9 \pm 0,29$ \\
\hline Выделено с мочой & $22,4 \pm 0,38$ & $21,6 \pm 0,19$ & $20,8 \pm 0,23$ \\
\hline Удержано в теле & $15,6 \pm 0,45$ & $17,3 \pm 0,26 *$ & $18,9 \pm 0,51^{* *}$ \\
\hline Использовано, \%: & \multicolumn{3}{|c|}{} \\
\hline $\begin{array}{l}\text { от принятого с } \\
\text { кормом }\end{array}$ & 25,4 & 28,1 & 30,7 \\
\hline от переваренного & 41,2 & 44,4 & 47,6 \\
\hline \multicolumn{4}{|c|}{ Баланс кальция } \\
\hline Принято с кормом & 22,2 & 22,2 & 22,2 \\
\hline Выделено с калом & $5,6 \pm 0,23$ & $4,8 \pm 0,22$ & $4,4 \pm 0,19$ \\
\hline Выделено с мочой & $1,4 \pm 0,09$ & $1,2 \pm 0,06$ & $1,1 \pm 0,06$ \\
\hline Удержано в теле & $15,2 \pm 0,30$ & $16,2 \pm 0,27 *$ & $16,7 \pm 0,15^{* *}$ \\
\hline $\begin{array}{l}\text { Использовано, \% } \\
\text { от принятого }\end{array}$ & $68,4 \pm 1,28$ & $73,0 \pm 1,28 *$ & $75,2 \pm 0,58^{* *}$ \\
\hline \multicolumn{3}{|c|}{ Баланс фосфора } \\
\hline Принято с кормом & 17,3 & 17,3 & 17,3 \\
\hline Выделено с калом & $4,8 \pm 0,39$ & $4,1 \pm 0,21$ & $3,8 \pm 0,58$ \\
\hline Выделено с мочой & $2,2 \pm 0,20$ & $2,2 \pm 0,12$ & $2,0 \pm 0,06$ \\
\hline Удержано в теле & $10,3 \pm 0,49$ & $10,4 \pm 0,32$ & $11,1 \pm 0,64$ \\
\hline $\begin{array}{l}\text { Использовано, \% } \\
\text { от принятого }\end{array}$ & $59,5 \pm 2,87$ & $63,6 \pm 1,87$ & $66,5 \pm 3,67$ \\
\hline
\end{tabular}

микрофлоры и пробиотической добавки оказывает активизирующее действие на белковый обмен в организме откармливаемого молодняка.

Достоверных межгрупповых различий по содержанию кальция и фосфора, уровня глюкозы в сыворотке крови обнаружено не было, как и по уровню резервной щелочности, которая находилась в пределах 48,3 - 49,4 ОБ\% $\mathrm{CO}_{2}$. 


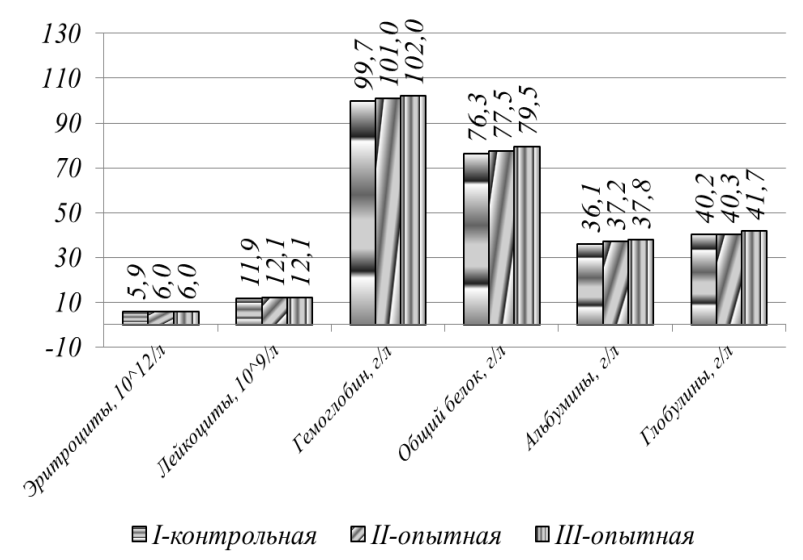

Рис. 2 - Морфологический состав крови и содержание белка в ее сыворотке у молодняка свиней на откорме под влиянием добавки «Проваген»

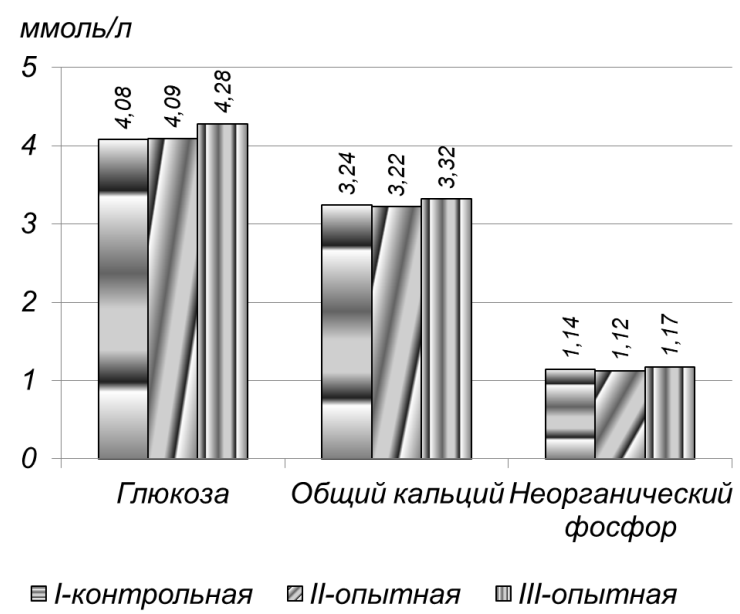

Рис. 3 - Некоторые биохимические показатели сыворотки крови у молодняка свиней на откорме под влиянием добавки «Проваген»

При достижении живой массы (в конце опыта) у молодняка свиней на откорме 100-101 кг был проведён контрольный убой. В результаты анализа убойных качеств молодняка свиней установлено, что выход мышечной ткани в опытных группах был больше на 0,8 и на 2,2\% аналогичного показателя контрольной группы. Установлено, что скармливание в период откорма животным кормосмеси, обогащённой пробиотической добавкой, не оказало существенного влияния на убойный выход, и он составил 71,9$72,4 \%$. Расчёт эффективности использования обменной энергии, поступившей из рациона, показал, что ее расход на основные физиологические функции организма и теплопродукцию, так называемые не продуктивные затраты составили в контрольной группе 63,8, во второй опытной группе - 64,0 и в третьей - 64,5\% и только на продуктивные цели ушло соответственно 36,2, 36,0 и 35,5\%, коэффициент полезного действия кормосмеси составил в контроле 26,5 и в опытных группах соответственно по 26,7 и 26,9\%.

\section{Обсуждение}

Применение пробиотических препаратов, по мнению ряда авторов, не только стимулирует активность ферментных систем, что оказывает действие на более рациональное использование энергии в организме, но и меняет в целом «картину» бикробиоты кишечника, оберегает полезную микрофлору и повышает резистентность организма [19- 25]. Экспериментальные данные, полученные нами, согласуются с этим мнением и свидетельствуют о благоприятном воздействии пробиотической добавки «Проваген» на процессы пищеварения и усвоения всего спектра поступивших питательных и жизненно необходимых веществ. Пищеварительный процесс животных в желудочно-кишечном тракте складывается из поступления корма в ротовую полость, ферментации, и при участии полезной микрофлоры. Под действием пробиотической добавки в составе кормосмеси нормализовалась микрофлора желудочно-кишечного тракта свиней с преимущественным развитием полезных микроорганизмов. Установлено, что с увеличением дозы пробиотической добавки в составе кормосмеси увеличивался и среднесуточный прирост. Экспериментальные данные подтверждают факт лучшего использования азота свиньями, получавшими кормосмесь с пробиотической добавкой в дозах 300 и 350 г/т, в том числе и переваренного, что по нашему мнению, связано с активацией ферментативных процессов под влиянием пробиотической добавки с усилением функции микроорганизмов в кишечнике молодняка свиней.

\section{Заключение}

Достоверно установлено, что скармливание кормосмеси ,обогащенной пробиотической добавкой «Проваген», откармливаемому молодняку свиней повышает уровень их среднесуточных приростов на $1,9(\mathrm{P}<0,01)$ и $2,6 \%$ $(\mathrm{P}<0,001)$ соответственно при дозах его включения 300 и 350 г/т . Включение в состав кормосмеси пробиотической добавки в расчете 350 г/т увеличивает переваримость сырого протеина на 2,7\% в сравнении с животными контрольной группы. Ежедневное скармливание пробиотической добавки позволяет более эффективно использовать и удерживать в теле азот: на 10,9\% - при дозе 300г/т и на 21,1\% - при дозе 350 г/т. Эффективность использования обменной энергии рациона в организме всех подопытных животных под действием пробиотической добавки существенно не отличается. Но более эффективно её использует молодняк свиней, который получал кормосмесь с добавкой 350 г/т. 


\section{Библиографический список}

1. Черноградская, Н.М. Использование нетрадиционных кормовых добавок в выращивании молодняка свиней в условиях Якутии/ H.M. Черноградская, М.Ф. Григорьев, А.И. Григорьева // Вестник КрасГАУ.- 2019.- № 12(153). - С. 176 181.

2. Продуктивность свиней при использовании в их рационах кормовой добавки с сорбирующими и пробиотическими свойствами/В.Е. Улитько, Ю.В. Семенова, Е.В. Савина, Л.А. Пыхтина, О.А. Десятов// Зоотехния. -2018.- № 7.- С.2527.

3. Улитько, В.Е. Биодобавки нового поколения в системе оптимизации питания и реализации биоресурсного потенциала животных: монография / В.Е. Улитько, Л.А. Пыхтина, О.А. Десятов [и др.]. -Ульяновск, 2015.- 512 с.

4. Ниязов, Н.С. Продуктивность свиней мясного типа при разных уровнях в рационах сырого протеина, обменной энергии и незаменимых аминокислот/ Н.С. Ниязов, О.Н. Родионова // Проблемы биологии продуктивных животных. - 2019. - №2. - С. 87-97.

5. Черекаев, А. Формула успеха в условиях глобального кризиса/А. Черекаев// Свинводство. -2020. - №4. - С. 17-19.

6. Махаев, Е.А. Совершенствование энергетического питания свиней / Е.А. Махаев, А.Т. Мысик // Зоотехния. - 2015. - №11.- С.7-9.

7. Влияние пробиотического комплекса на продуктивные качества и обменные процессы у растущего откармливаемого молодняка свиней / Н.М. Магомедалиев, Р.В. Некрасов, М.Г. Чабаев, В.В. Джавахия, Е.В. Глаголева, М.И. Карташов // Аграрная наука. - 2020. - № 1. - С.22-26.

8. Gamko, L.N. Probiotic additives in the rings of young pigs under the conditions of technogenous environmental pollution / L.N. Gamko, T.L. Talyzina, V.V. Talyzin // Research Journal of Pharmaceutical, Biological and Chemical Sciences. - 2019. - T. 10. № 1. - C. 1853-1859.

9. Thacker, P.A. Alternatives to antibiotics as growth promoters for use in swine production: Arevrew. J. Anim. Sci. Biotechnol.2013.4.35.

10. Талызина, Т.Л. Влияние пробиотических добавок на биохимические показатели крови свиноматок и их потомства/ Т. Л. Талызина, Ю.С. Коптева // Интенсивность и конкурентоспособность отраслей животноводства. Материалы Международной научно-практической конференции.- Брянск, 2016. - С. 288-295.

11. Бетин, А.Н. Применение пробиотического препарата БИОПЛЮС ҮС свиньям / А. Н. Бетин // Ветеринария. -2020. - № 5. - С. 53-56.

12. Шостя, А.М., Особенности влияния пробиотического препарата «БАЙКАЛ - ЭМ 1 У» на метаболический статус и продуктивность свиней/ А. М. Шостя, С.Г. Зиновьев // Зоотехническая наука Беларуси. - 2015. - Т. 50. - № 2. - С. 112-119.

13. Сеин, О.Б. Влияние пробиотического препарата «Муцинол» на физиолого-биохимический статус свиней / О.Б. Сеин, Д. П. Черников // Вестник Курской государственной сельскохозяйственной академии.- 2018. - № 4.- С. 115-118.

14. Пивторак, Я.И. Перспективы использования пробиотических кормовых добавок в питании свиней/ Я. И. Пивторак, И. М. Богдан // Науковий вісник Львівського національного університету ветеринарної медицини та біотехнологій імені С.3. Ґжицького. 2015. - Т. 17. № 1-3 (61).- С. 151-156.

15. Забашта, Н.Н. Воздействие пробиотических средств на продуктивность свиней/ $\mathrm{H}$. Н. Забашта, Е.Н. Головко, И.А. Синельщикова // Сборник научных трудов Краснодарского научного центра по зоотехнии и ветеринарии. - 2018. - T. 7. - № 1.- С. 258-264.

16. Лукьянчикова, Е. / Оптимизация микрофлоры кишечника - путь к повышению продуктивности / Е. Лукьянчикова, С. Шеламов // Свиноводство. - 2016. №3. - С.65-66.

17. Овчинников, А.А. Влияние Глаукарина на переваримость питательных веществ рациона молодняка свиней на откорме / А.А. Овчинников, Е.М. Ермолова // Вестник мясного скотоводства. - 2016. - №4. - С.154-160.

18. Новое поколение пробиотических препаратов кормового назначения / Н.А. Ушакова, Р.В. Некрасов, В.Г. Правдин [и др.] // Фундаментальные исследования. - 2012. - № 1. - С. 184192.

19. Valeriano, V.D. Probiotic roles of Lactobacillus sp. in swine: insights from gut microbiota / V.D. Valeriano, M.P. Balolong, D.K. Kang // J. Appl Microbiol., 2017, 122 (3): 554-567.

20. . Влияние скармливание поросятам пробиотика «Гидролактив» на их рост и мясные качества / Г.С. Походня, Н.А. Маслова, Т.А. Малахова // Вестник Курской ГСХА. - 2016. - № 9. - С. 147-152.

21. Войтенко О.С., Войтенко Л.Г., Гнидина Ю.С. Рост, сохранность, репродукция свиней и продукты переработки свиноводства при применении пробиотических препаратов / О.С. Войтенко, Л.Г. Войтенко, Ю.С. Гнидина // Научная жизнь. - 2019.- №2. - С. 86-92.

22. Immunomodulating effects of probiotics for microbiota modulation, gut health and disease resistance in pigs / M/ Roselli, R. Pieper, C. RogelGaillard, H. Smidt, C. Lauridsen // Animal Feed Science and Technology. - 2017. - № 3. - P. 180-186

23. Повышение продуктивности выращиваемых с 1 до 2 месяцев поросят при скармливании им кормовой добавки «ГидроЛактиВ» / А.Т. 
Мысик, Г.С. Походня, Т.А. Малахова, С.А. Жабинская // Зоотехния. - 2016.- № 11. - С. 21-23.

24. Использование нового пробиотика Энзимспорин при выращивании молодняка свиней / Р.В. Некрасов, М.Г. Чабаев, И.М. Магомедалиев, А.А. Зеленченкова, Е.В. Глаголева, М.И. Карташов // Зоотехния. - 2016. - №10. - С.13-17.

25. Фархутдинова, А.Р. Влияние использования пробиотиков нового поколения, на приме- ре «Байкал ЭМ-1» / А.Р. Фархутдинова, М.Г. Маликова // Состояние и перспективы увеличения производства высококачественной продукции сельского хозяйства: материалы Всероссийской научно-практической конференции с международным участием. ФГБОУ ВПО Башкирский государственный аграрный университет. Факультет пищевых технологий. Кафедра технологии мяса и молока.- 2013.- С. 7-10.

\title{
EXCHANGE OF MATTER AND ENERGY IN FATTENING STORE PIGS DURING FEEDING PROBIOTIC-SUPLEMENTED FEED MIX
}

\author{
Gamko L.N. ${ }^{1}$, Sidorov I.I. ${ }^{2}$, Menyakina A. G. ${ }^{1}$, \\ ${ }^{1}$ FSBEI HE Bryansk state agrarian university \\ 243365, Bryansk region, Vygotnichsky district, Kokino village, Sovetskaya street, $2 a$ \\ +79102357733, e-mail: menyakina77@yandex.ru \\ ${ }^{2}$ FSBI Bryansk Interregional veterinary laboratory
}

2241520, Bryansk region, Bryansk district, Suponevo village, Sosheinaya street - 7; tel.: 8 (4832) 92-24-84

Key words: store pigs, feed mix, productivity, digestibility, balance, In the article the research results on feeding fattening store pigs using in its cmposition 300 and $350 \mathrm{~g} / \mathrm{t}$ of probiotic additive during daily feeding 2, $23 \mathrm{~kg}$ of feed mix in average per experiment. The research object fattening store pigs of large white with middle body weight $38,6-39,0 \mathrm{~kg}$ and probiotic additive «Provagen». Store pigs for experiment were selected from sows, which were fed for 30 days before farrow by probiotic additive at the same doze in composition of feed mix. Absolute liveweight gain for reference period was 60, 4 in control group, in the second experiment group 61,5 and in the third $62,0 \mathrm{~kg}$. Daily average was respectively 525,535 and $539 \mathrm{~g}$. Coefficients for digestibility of nutritious matters of feed mix with probiotic additive were higher, especially in the third experimental group-crude fat and crude fiber for 4,1 and $49,8 \%$.Daily average balance of nitrogen, calcium and phosphorus were positive. Nitrogen of store pigs was held in the second experimental group for 10,9 and in the third for $21,2 \%$ more in comparison to the control group. Morphological and biochemical blood indicators were within physiological normal state. Feeding probiotic additive as part of feed mix for fattening store pigs allowed to find out more effective doze of probiotic additive introduction in feed mix during integrated research for $-350 \mathrm{~g} / \mathrm{t}$.

Bibliography

1. Chernogradskaya, N.M. The use of alternative feed additives in breeding of young pigs in Yakutia / N.M. Chernogradskaya, M.F. Grigoryev, A.I. Grigoryeva // Vestnik of KrasSAU.- 2019.- № 12(153). - P. 176-181.

2. Productivity of pigs when using a feed additive with sorbing and probiotic properties in their diets N.E. Ulitko, Yu.V. Semenova, E.V. Savina, L.A. Pykhtina, O.A. Desyatov//Zootechnics. -2018.- № 7.- P.25-27.

3. Ulitko, V.E. Bioadditives of new generation in the system of nutrition optimization and realization of the bioresource potential of animals: monograph / V.E. Ulitko, L.A. Pykhtina, O.A. Desyatov [et al.]. -Ulyanovsk, 2015.-512p.

4. Niyazov, N.S. Productivity of meat-type pigs at different levels in the diets of raw protein, metabolic energy and essential amino acids / N.S. Niyazov, O.N. Rodionova // Problems of biology of productive animals. 2019, - No2, - P. 87-97.

5. Cherekaev, A. Formula for success in a global crisis /A. Cherekaev// Pig breeding. -2020. - №4. - P. 17-19.

6. Makhaev, E.A. Improving the energy supply of pigs / E.A. Makhaev, A.T. Mysik // Zootechnics. - 2015. - №11.- P.7-9.

7. The influence of probiotic complex on productive qualities and metabolic processes in growing fatten young pigs / N.M. Magomedaliev, R.V. Nekrasov, M.G. Chabaev, V.V. Dzhavakhiya, E.V. Glagoleva, M.I. Kartashov // Agrarian science. - 2020. - № 1. - P.22-26.

8. Gamko, L.N. Probiotic additives in the rings of young pigs under the conditions of technogenous environmental pollution / L.N. Gamko, T.L. Talyzina, V.V. Talyzin // Research Journal of Pharmaceutical, Biological and Chemical Sciences. - 2019. - T. 10. - № 1. - C. 1853-1859.

9. Thacker, P.A. Alternatives to antibiotics as growth promoters for use in swine production: Arevrew. J. Anim. Sci. Biotechnol.2013.4.35.

10. Talyzina, T.L. Influence of probiotic supplements on the biochemical parameters of sows blood and their offspring / T. L. Talyzina, Yu.S. Kopteva // The intensity and competitiveness of livestock industries. Materials of the International research to practice conference.- Bryansk, 2016. - P. 288-295.

11. Betin, A.N. Application of probiotic preparation BIOPLUS YC to pigs / A. N. Betin // Veterinary. -2020. - № 5. - P. 53-56.

12. Shostya, A.M., Features of the effect of probiotic preparation "BAIKAL - EM 1 U" on the metabolic status and productivity of pigs / A. M. Shostya, S.G. Zinovyev // Zootechnical science of Belarus. - 2015. - V. 50. - № 2. - P. 112-119.

13. Sein, O.B. The influence of probiotic preparation "Mutsinol" on physiological and biochemical status of pigs / O.B. Sein, D. P. Chernikov //Vestnik of Kursk state agricultural academy.- 2018. - № 4.- P. 115-118.

14. Pivtoryak, Ya.I. Perspectives of using probiotic feed additives in pig nutrition / Ya. I. Pivtoryak, I. M. Bogdan // Scientific Vestnik of Lvov national University of veterinary medicine and biotechnologies named after S. Z. Gzhitskigo. 2015. - V. 17. - № 1-3 (61).- P. 151-156.

15. Zabashta, N.N. The influence of probiotic agents on pig productivity / N. N. Zabashta, E.N. Golovko, I.A. Sinelshikova // Collection of scientific papers of Krasnodar scientific center for animal science and veterinary medicine.- 2018. - V. 7. - № 1.- P. 258-264.

16. Lukyanchikova, E. / Optimization of the intestinal microflora - the way to increase productivity / E. Lukyanchikova, S. Shelamov // Pig breeding. - 2016. №3. - $P$.65-66.

17. Ovchinnikov, A.A. Glucamine influence on the nutrient digestibility of the diet of young pigs on fattening / A.A. Ovchinnikov, E.M. Ermolova // Vestnik of meat cattle breeding. - 2016. - №4. - P.154-160.

18. A new generation of feed-based probiotic preparations / N.A. Ushakova, R.V. Nekrasov, V.G. Pravdin [et al.] // Fundamental research. - 2012. - No 1. - P. 184-192.

19. Valeriano, V.D. Probiotic roles of Lactobacillus sp. in swine: insights from gut microbiota / V.D. Valeriano, M.P. Balolong, D.K. Kang // J. Appl Microbiol., 2017, $122(3):$ 554-567.

20. . The effect of feeding piglets probiotic "Hydrolaktiv" on their growth and meat quality / G.S. Pokhodnya, N.A. Maslova, T.A. Malakhova // Vestnik of Kursk SAA. - 2016. - № 9. - P. 147-152.

21. Voitenko O.S., Voitenko L.G., Gnidina Yu.S. Growth, safety, reproduction of pigs and pig processing products when using probiotic preparations / O.S. Voitenko, L.G. Voitenko, Yu.S. Gnidina // Scientific life. - 2019.- №2. - P. 86-92.

22. Immunomodulating effects of probiotics for microbiota modulation, gut health and disease resistance in pigs $/ M /$ Roselli, R. Pieper, C. Rogel-Gaillard, $H$. Smidt, C. Lauridsen // Animal Feed Science and Technology. - 2017. - № 3. - P. 180-186

23. Increasing the productivity of piglets grown from 1 to 2 months when feeding them the feed additive "Hydrolaktiv» / A.T. Mysik, G.S. Pokhodnya, T.A. Malakhova, S.A. Zhabinskaya // Zootechnics. - 2016.- № 11. - P. 21-23.

24. The use of a new probiotic Enzymesporine during the rearing of young pigs / R.V. Nekrasov, M.G. Chabaev, I.M. Magomedaliev, A.A. Zelenchenkova, E.V. Glagoleva, M.I. Kartashov // Zootechnics. - 2016. - №10. - p.13-17.

25. Fakhrutdinova, A.R. Influence of use of new generation probiotics, on the example of "Baikal EM-1" / A. R. Farkhutdinova, M. G. Malikova // State and prospects of increasing the production of high-quality agricultural products: proceedings of All-Russian research to practice conference with international participation. FSBEI HE Bashkir state agrarian university. Faculty of food technologies. Department of meat and milk technology- 2013.- P. 7-10. 